\title{
Oxygen-Reconstituted Active Species of Single-Atom Cu Catalysts for Oxygen Reduction Reaction
}

\author{
Liu Yang, ${ }^{1}$ Haoxiang Xu, ${ }^{1}$ Huibing Liu, ${ }^{1}$ Xiaofei Zeng, ${ }^{1}$ Daojian Cheng, ${ }^{1}$ Yan Huang, \\ Lirong Zheng, ${ }^{2}$ Rui Cao, ${ }^{3}$ and Dapeng Cao ${ }^{1}$ \\ ${ }^{1}$ Beijing Advanced Innovation Center for Soft Matter Science and Engineering, State Key Laboratory of Organic- \\ Inorganic Composites, Beijing University of Chemical Technology, Beijing 100029, China \\ ${ }^{2}$ Beijing Synchrotron Radiation Facility, Institute of High Energy Physics, Chinese Academy of Sciences, Beijing 100049, China \\ ${ }^{3}$ Stanford Synchrotron Radiation Lightsource, SLAC National Accelerator Laboratory, Menlo Park, California 94025, USA
}

Correspondence should be addressed to Dapeng Cao; caodp@mail.buct.edu.cn

Received 27 June 2020; Accepted 31 August 2020; Published 5 October 2020

Copyright @ 2020 Liu Yang et al. Exclusive Licensee Science and Technology Review Publishing House. Distributed under a Creative Commons Attribution License (CC BY 4.0).

\begin{abstract}
Identification of an active center of catalysts under realistic working conditions of oxygen reduction reaction (ORR) still remains a great challenge and unclear. Herein, we synthesize the $\mathrm{Cu}$ single atom embedded on nitrogen-doped graphene-like matrix electrocatalyst (abbreviated as SA-Cu/NG). The results show that SA-Cu/NG possesses a higher ORR capability than $20 \% \mathrm{Pt} / \mathrm{C}$ at alkaline solution while the inferior activity to $20 \% \mathrm{Pt} / \mathrm{C}$ at acidic medium. Based on the experiment and simulation calculation, we identify the atomic structure of $\mathrm{Cu}-\mathrm{N}_{2} \mathrm{C}_{2}$ in SA-Cu/NG and for the first time unravels that the oxygenreconstituted $\mathrm{Cu}-\mathrm{N}_{2} \mathrm{C}_{2}-\mathrm{O}$ structure is really the active species of alkaline ORR, while the oxygen reconstitution does not happen at acidic medium. The finding of oxygen-reconstituted active species of SA-Cu/NG at alkaline media successfully unveils the bottleneck puzzle of why the performance of ORR catalysts at alkaline solution is better than that at acidic media, which provides new physical insight into the development of new ORR catalysts.
\end{abstract}

\section{Introduction}

When energy consumption is rapidly rising, the resulting environmental issues have become serious [1]. Therefore, developing green and sustainable energies is the key to solve existing questions [2]. Oxygen reduction reaction (ORR) is considered as a crucial electrochemical reaction, and it often determines the performance of new energy devices like fuel cells and other energy storage equipment [3-7]. At present, the platinum $(\mathrm{Pt})$ relative nanomaterials are still the stateof-the-art catalysts for the ORR, which significantly hinders the commercialization of these devices due to the rareness of precious Pt [8].

Recently, atomically dispersed transition metal/nitrogen$(\mathrm{N}-)$ doped porous carbons $(\mathrm{M}-\mathrm{N}-\mathrm{C})$ are regarded as valuable nonnoble metal catalysts to substitute for commercial Pt [9-12], including Fe- [13-18], Co- [19-21], Mn- [22, $23]$, and $\mathrm{Ru}-[24,25]$ based $\mathrm{M}-\mathrm{N}-\mathrm{C}$ catalysts. Inspired that $\mathrm{Cu}$ compounds can effectively catalyze the reductive activation of $\mathrm{O}_{2}$ in enzymes and the protein lactase, increasing investigations indicate that the single-atom $\mathrm{Cu}$ catalysts (Cu-SACs) can also serve as excellent ORR catalysts. For example, $\mathrm{Cu}-\mathrm{N}-\mathrm{C}$ moieties can become highly efficient active sites by adjusting the valance state of $\mathrm{Cu}$ atom toward $\mathrm{Cu}(\mathrm{II})$ or $\mathrm{Cu}(\mathrm{I})$ by engineering coordination environment of $\mathrm{Cu}-\mathrm{N}$ $\mathrm{C}$ moieties [26-28]. And some useful strategies have also been developed to synthesize the Cu-SACs trapped on nitrogen-rich porous carbon with large-scale or high load contents [29-31]. Although these studies have shown that the $\mathrm{Cu}$-SACs possess high ORR activity, the critical question of "what are the realistic active sites of Cu-SACs for ORR?" is unclear yet and in dispute. Due to the high similarities of bond lengths of metal-nitrogen/metal-carbon/metal-oxygen, as well as pyridine/pyrrole species, the extended X-ray absorption fine structure (EXAFS) fitting still is not able to accurately analyze the precise configuration of these samples in $\mathrm{R}$ space. Moreover, the atomically dispersed M-N-C catalysts from different synthesis methods also often possess different coordination environments and active species. In fact, the experimental explanation on active species of $\mathrm{Cu}-\mathrm{SACs}$ 
for ORR is still severely dependent on X-ray absorption nearedge structure (XANES) and EXAFS without better techniques. Among them, the carbon-hosted $\mathrm{CuN}_{4}$ moiety has been proposed to be considered as an active center of $\mathrm{Cu}$ SACs $[27-29,31,32]$, based on the coordination number (4) of $\mathrm{Cu}$ in the microstructure. Nevertheless, with a computational hydrogen electrode (CHE) model, the wellestablished $\mathrm{Cu}-\mathrm{SAC}$ model with $\mathrm{CuN}_{4}$ center possesses rather inferior ORR activity to $\mathrm{Pt}(111)$ according to the theoretical onset potential $(0.25 \sim 0.43 \mathrm{~V}$ vs. $0.79 \mathrm{~V})[27,28,31-$ 33 ], which indicates that the atomic-level understanding on the active center of $\mathrm{Cu}-\mathrm{SACs}$ boosting ORR remains controversial. More importantly, previous studies demonstrated that numerous catalysts experienced reconstruction during the test operation, probably originating from some physical and chemical aspects, such as $\mathrm{pH}$, potential polarization, and adsorbates [34-36]. Therefore, identification of the definite active-site structure and thermodynamics intermediate transformation on $\mathrm{Cu}-\mathrm{N}-\mathrm{C}$ catalysts under ORR working conditions are required urgently, which is significantly important for intelligent fabrication of fresh ORR SACs.

Herein, we use the surfactant-assisted synthesis method to successfully prepare the single-atom $\mathrm{Cu}$ embedded on an $\mathrm{N}$-doped graphene-like matrix (abbreviated as $\mathrm{SA}-\mathrm{Cu} / \mathrm{NG}$ ). The synthesized catalyst displays superior ORR property than $20 \% \mathrm{Pt} / \mathrm{C}$ at $0.1 \mathrm{M} \mathrm{KOH}$ electrolyte, while inferior ORR performance to $20 \% \mathrm{Pt} / \mathrm{C}$ at acidic solution. Based on the XAS and the systematic search for possible configurations by density functional theory (DFT) calculations, we identified the atomic structure of the $\mathrm{CuN}_{2} \mathrm{C}_{2}$ moiety embedded in porous graphene-like nanosheets for $\mathrm{SA}-\mathrm{Cu} / \mathrm{NG}$. We also found that the reconstitution of active species of $\mathrm{Cu}-\mathrm{N}_{2} \mathrm{C}_{2}$ under ORR working condition was induced by dynamic adsorption of atomic oxygen $\left(\mathrm{O}^{*}\right)$ intermediate on the $\mathrm{Cu}$ $\mathrm{C}$ site (marked as $\mathrm{Cu}-\mathrm{N}_{2} \mathrm{C}_{2}-\mathrm{O}$ ), and the oxygenreconstituted $\mathrm{Cu}-\mathrm{N}_{2} \mathrm{C}_{2}-\mathrm{O}$ structure is the real active species of SA-Cu/NG for ORR at alkaline condition. The oxygenreconstituted $\mathrm{Cu}-\mathrm{N}_{2} \mathrm{C}_{2}-\mathrm{O}$ structure accounts for superior ORR activity of $\mathrm{SA}-\mathrm{Cu} / \mathrm{NG}$ to $\mathrm{Pt} / \mathrm{C}$ at alkaline condition, while the virgin $\mathrm{Cu}-\mathrm{N}_{2} \mathrm{C}_{2}$ is responsible for inferior activity to $\mathrm{Pt} / \mathrm{C}$ at acidic medium. The finding of oxygenreconstituted active species at alkaline media unveils the bottleneck puzzle of why the activity of the ORR catalyst at alkaline condition is always superior to the one at acidic solution.

\section{Results and Discussion}

2.1. The Characterization of SA-Cu/NG. The single-atom $\mathrm{Cu}$ embedded on $\mathrm{N}$-doped graphene-like matrix (SA-Cu/NG) was synthesized via the modified surfactant-assisted method from our group, and the detailed synthesis steps are presented in Supplementary Materials (available here). The scanning electron microscope (SEM) image displays that the SA-Cu/NG possesses petal-like morphologies that are made up of porous thin nanosheets (Figure 1(a)). The transmission electron microscope (TEM) image exhibits the graphene-like flakes of the as-prepared SA-Cu/NG sample without aggregation of $\mathrm{Cu}$ nanoparticles (Figure 1(b)), even under high-resolution TEM (HRTEM) in Figure 1(c). This phenomenon is also proved by XRD, where no obvious diffraction peaks are detected for SA-Cu/NG sample in Figure S1. Impressively, numerous atomic-level brightened dots are detected at a high-angle annular dark-field (HAADF) pattern (Figure $1(\mathrm{~d})$ ), corresponding to heavy copper atoms (Figure 1(d) and Figure S2). Furthermore, the EELS mappings (Figures $1(\mathrm{e})-1(\mathrm{i})$ ) reveal that the $\mathrm{Cu}, \mathrm{C}$, and $\mathrm{N}$ are homogeneously dispersed on the surface of SA-Cu/NG, and the overlay mode image (Figure 1(i)) discloses that the $\mathrm{Cu}$ atoms are surrounded with $\mathrm{N}$.

To explore the valence state, composition of the element sample, and surrounding coordination environment of $\mathrm{Cu}$, X-ray photoelectron spectroscopy (XPS), XANES, and EXAFS are applied. In Figure S3 and Table S1, the XPS spectrum displays that the SA-Cu/NG contains nitrogen of 6.34 at $\%$ and $\mathrm{Cu}$ of 0.56 at $\%$. The $\mathrm{N} 1$ s spectrum for SA-Cu/NG can be fitted to four types [37]. Notably, after atomic $\mathrm{Cu}$ is doped into porous carbon, the proportion of pyrrolic $\mathrm{N} / \mathrm{Cu}-\mathrm{N}$ increased, indicating that the $\mathrm{Cu}-\mathrm{N}$ moiety is formed in the SA-Cu/NG sample (Figures S4 and S5). Moreover, the $\mathrm{Cu} 2 \mathrm{p}$ curve shows two peaks at $935.4 \mathrm{eV}$ and $955.2 \mathrm{eV}$, attributed to $\mathrm{Cu}^{2+2} \mathrm{p}_{3 / 2}$ and $2 \mathrm{p}_{1 / 2}$. $\mathrm{Cu} 2 \mathrm{p}$ satellites at $944.3 \mathrm{eV}$ indicate the existence of an unfilled electron (Figure S6) $[26,38]$.

The $\mathrm{Cu}$ K-edge XANES and the EXAFS of SA-Cu/NG are also used to explore the local structure of SA-Cu/NG with the standard $\mathrm{Cu}$ foil, $\mathrm{Cu}_{2} \mathrm{O}$, and $\mathrm{CuO}$ as counterparts. The valence of $\mathrm{Cu}$ in $\mathrm{SA}-\mathrm{Cu} / \mathrm{NG}$ is found between $\mathrm{Cu}(\mathrm{I})$ and $\mathrm{Cu}(\mathrm{II})$, because the XANES curve for SA-Cu/NG shifts to the higher energy than the $\mathrm{Cu}$ foil and $\mathrm{Cu}_{2} \mathrm{O}$, while slightly lower energy than standard $\mathrm{CuO}$ (Figure 2(a)). To calculate the $\mathrm{Cu}$ oxidation valence, the fitting curves derived from the first maximum in the first-order derivative of $\mathrm{Cu} \mathrm{K}$ edge XANES are depicted in Figures 2(b) and 2(c), and the $\mathrm{Cu}$ average valence state of $\mathrm{SA}-\mathrm{Cu} / \mathrm{NG}$ is about +1.46 . The intuitionistic structural information on $\mathrm{Cu}$ atoms can be obtained from the EXAFS via Fourier transforms (FT) (Figure $2(\mathrm{~d})$ ), where the SA-Cu/NG exhibits a peak around $1.56 \AA$ (phase uncorrected) attributed to the $\mathrm{Cu}-\mathrm{N}$ bond (or $\mathrm{Cu}-\mathrm{C}$ bond), and a satellite peak corresponds to second shell $\mathrm{Cu}-\mathrm{C}$ bond (at about $2.35 \AA$ ). No obvious peak around $2.2 \AA$ ( $\mathrm{Cu}-\mathrm{Cu}$ bond) is observed in the $\mathrm{SA}-\mathrm{Cu} / \mathrm{NG}$ sample compared to what is found in the $\mathrm{Cu}_{2} \mathrm{O}$ and $\mathrm{CuO}$ (Figure 2(d), blue and cyan trances), which suggests that the $\mathrm{Cu}$ atoms do not aggregate into nanoparticles that are connected by $\mathrm{Cu}-\mathrm{Cu}$ bond. The observation is in agreement with the XRD and STEM. EXAFS fitting on the first shell of SA$\mathrm{Cu} / \mathrm{NG}$ catalyst (Figure 2(e)) exhibits that the configuration for the $\mathrm{SA}-\mathrm{Cu} / \mathrm{NG}$ catalysts is one $\mathrm{Cu}$ coordinated with four surrounding nitrogen or carbon, and the fitting information is gathered in Table S2. EXAFS wavelet transform (WT) analysis is used as a precise technique to distinguish the similar backscattering atoms based on resolutions in both $k$ and $R$ spaces. As shown in Figure 2(f), the Cu-SA/NG exhibits one obvious maximum at approximatively $4.5 \AA^{-1}$, which is ascribed to the $\mathrm{Cu}-\mathrm{N}(\mathrm{C})$ bonding, and no $\mathrm{Cu}-\mathrm{Cu}$ bond is discovered. Impressively, compared with the $\mathrm{CuPc}$ standard sample, SA-Cu/NG shows a slightly shift position in maximum intensity, indicating that atomic $\mathrm{Cu}$ in the SA-Cu/NG 


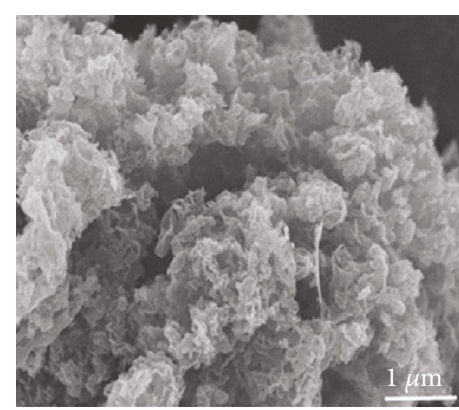

(a)

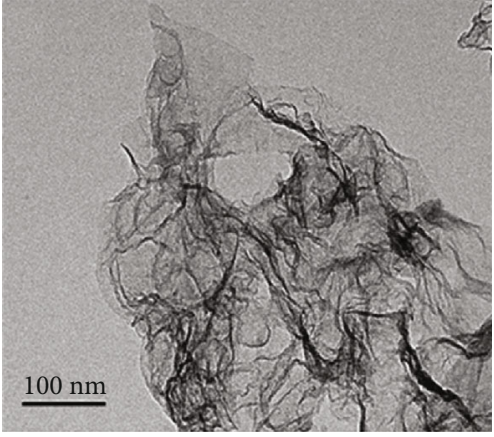

(b)

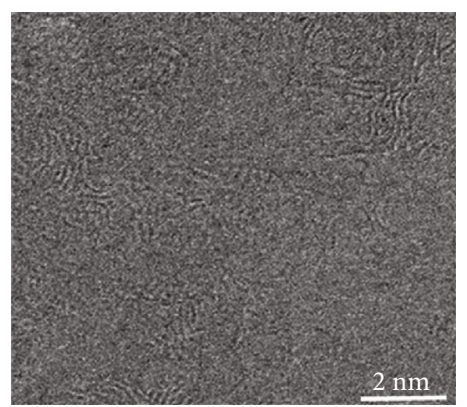

(c)

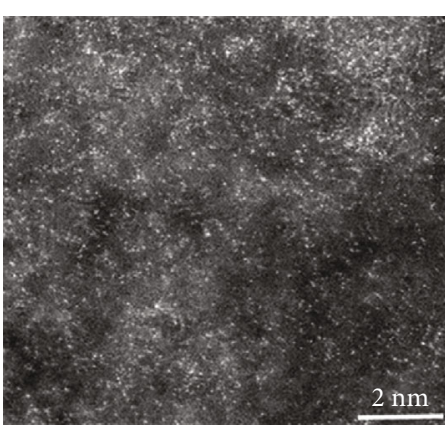

(d)

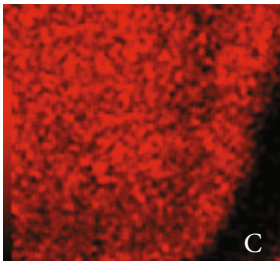

(f)

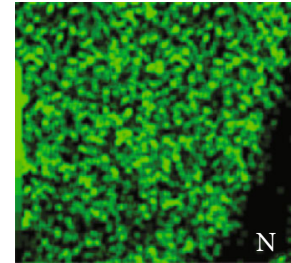

(g)

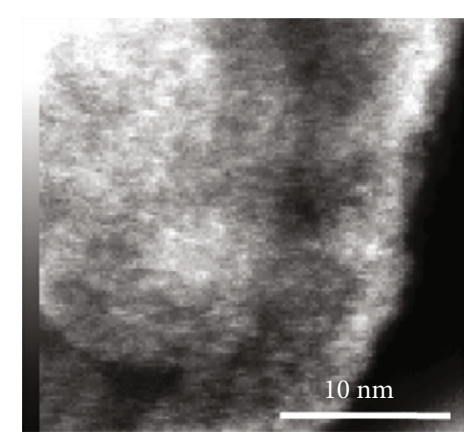

(e)

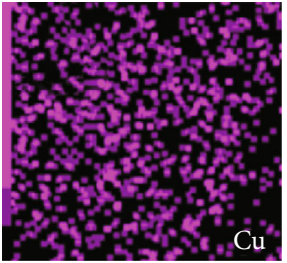

(h)

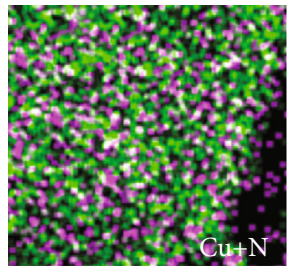

(i)

FIGURE 1: Morphologies of samples: (a) the SEM image, (b) TEM image, (c) HRTEM image, and (d) HAADF STEM image for SA-Cu/NG. (ei) EELS mapping of $\mathrm{C}, \mathrm{N}, \mathrm{Cu}$, and overlying $\mathrm{Cu}$ and $\mathrm{N}$ for $\mathrm{SA}-\mathrm{Cu} / \mathrm{NG}$ sample.

sample coordinates not only with nitrogen but also with the adjacent carbon. However, this phenomenon cannot be analyzed from $R$ space of Cu EXAFS experimentally.

As well known, the performance of the catalysts is related to the intrinsic activity and the number of active centers accessible, so the porosity of the samples is also explored. Interestingly, the $\mathrm{SA}-\mathrm{Cu} / \mathrm{NG}$ has a high surface area $\left(884 \mathrm{~m}^{2} \mathrm{~g}^{-1}\right)$ and excellent pore property $\left(1.97 \mathrm{~cm}^{3} \mathrm{~g}^{-1}\right)$ (Figures S7 and S8 and Table S3). This high porosity of SA$\mathrm{Cu} / \mathrm{NG}$ is beneficial to contact abundant catalytic centers and transfer electrons [39].

2.2. Alkaline ORR Tests. The electrochemical tests are conducted in $0.1 \mathrm{M} \mathrm{KOH}$ solution to investigate the ORR performance of SA-Cu/NG, NG, and 20\% Pt/C. In Figure 3(a), the NG displays the general electrochemical curve, verified by the half-wave potential $\left(E_{1 / 2}\right)$ of $0.8 \mathrm{~V}$ (versus RHE), indicating that the N-doped carbon can catalyze ORR but not highly efficient. Impressively, when the small quantity of $\mathrm{Cu}$ is introduced into the NG sample, a leap increase of ORR activity is observed for the SA-Cu/NG sample, which indicates that the SA-Cu/NG with mixed valence is highly efficient for ORR. $E_{1 / 2}$ of $0.856 \mathrm{~V}$ (versus RHE) is obtained for SA$\mathrm{Cu} / \mathrm{NG}$, more excellent than $20 \% \mathrm{Pt}\left(E_{1 / 2}\right.$ of $0.844 \mathrm{~V}$, versus $\mathrm{RHE})$. The excellent activity for $\mathrm{SA}-\mathrm{Cu} / \mathrm{NG}$ is comparable with the majority previously published for nonnoble metal electrocatalysts [10, 40-48]. Remarkably, the SA-Cu/NG also shows large kinetic current density $\left(J_{\mathrm{k}}\right)$ of $6.84 \mathrm{~mA} / \mathrm{cm}^{2}$ at $0.85 \mathrm{~V}$ (versus RHE), which is 11.4 times of $\mathrm{NG}\left(0.6 \mathrm{~mA} / \mathrm{cm}^{2}\right)$ and 1.4 -folds of $20 \% \mathrm{Pt} / \mathrm{C}\left(5 \mathrm{~mA} / \mathrm{cm}^{2}\right)$, respectively (Figure S9). A small Tafel slope $\left(59.1 \mathrm{mV} \mathrm{dec}^{-1}\right)$ further verifies the more outstanding activity of SA-Cu/NG to $20 \% \mathrm{Pt} / \mathrm{C}$ $\left(92.6 \mathrm{mV}\right.$ decade $^{-1}$ ) (Figure 3(b)). The selectivity and kinetic of SA-Cu/NG are studied. As shown in Figures S10 and S11, based on slopes of the Koutecky-Levich (K-L) equation, the transfer electron number $(n)$ is obtained. The SA-Cu/NG is 3.95 at $0.7 \mathrm{~V}$ (versus RHE), better than NG (3.74 at $0.3 \mathrm{~V}$, versus RHE) and comparable to commercial $\mathrm{Pt} / \mathrm{C}$ catalyst. This phenomenon indicates the outstanding $4 \mathrm{e}^{-}$selectivity of SA-Cu/NG in 0.1 M KOH. Moreover, Figure 3(c) shows that the RRDE-measured $\mathrm{HO}_{2}{ }^{-}$yields for SA-Cu/NG are not more than $5.3 \%$ within $0.2-0.8 \mathrm{~V}$ in $0.1 \mathrm{M} \mathrm{KOH}$, which is extremely lower than the NG sample $(<19 \%)$. Similarly, $n$ for SA-Cu/NG from RRDE measurement is 3.89-3.96 in the 


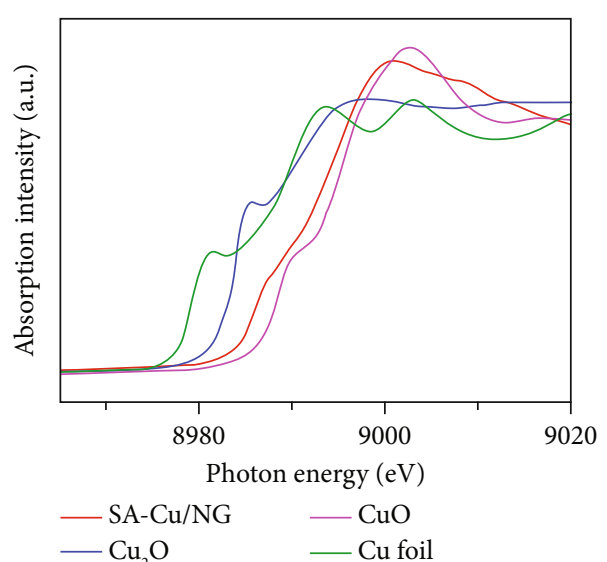

(a)

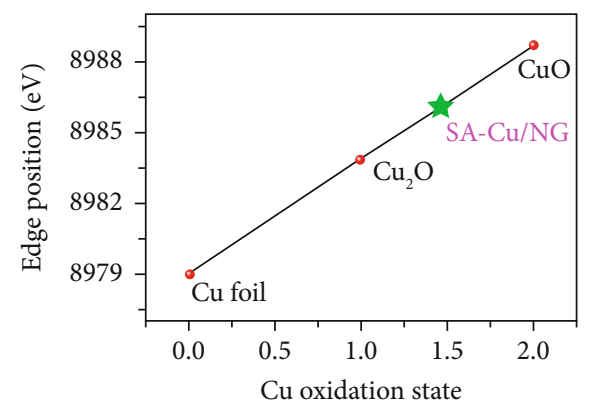

(c)

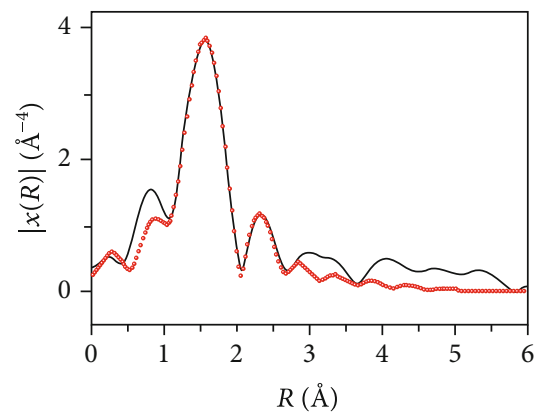

- SA-Cu/NG

(e)

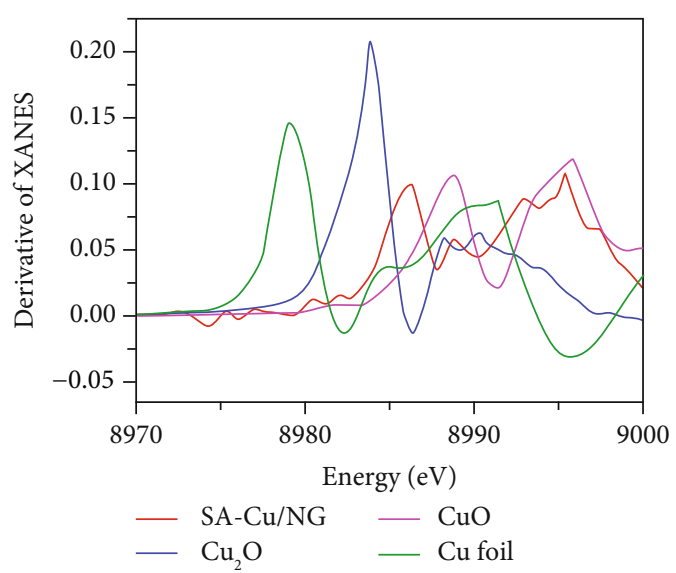

(b)

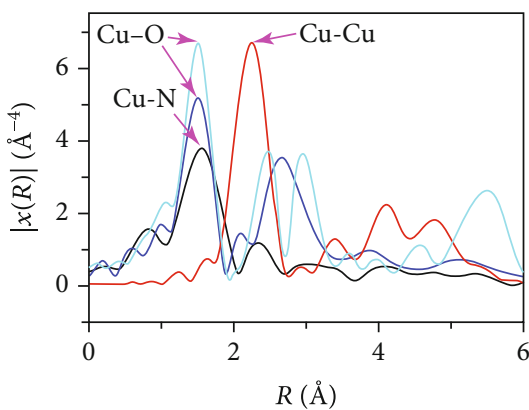

$-\mathrm{SA}-\mathrm{Cu} / \mathrm{NG}-\mathrm{Cu}_{2} \mathrm{O}$

$-\mathrm{Cu}$ foil ${ }^{*} 0.3-\mathrm{CuO}$

(d)

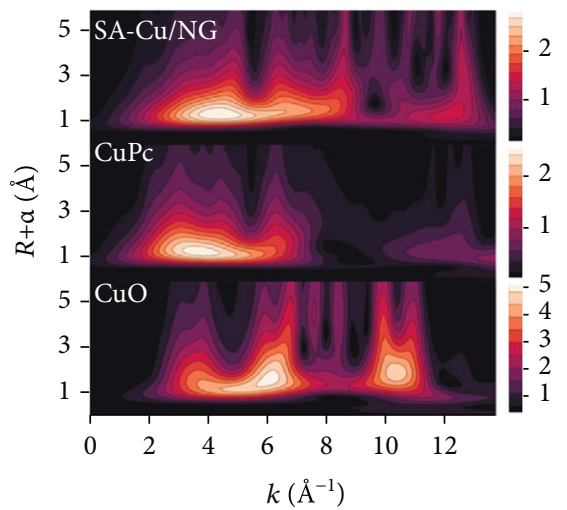

(f)

FIgURE 2: The structure characterization of samples: (a) XANES spectra, (b) derivative of normalized XANES of Cu K-edge, (c) the fitting valence of $\mathrm{Cu}$ extracted from XANES, (d) Fourier transforms of Cu K-edge spectra, (e) wavelet transform (WT), and (f) EXAFS fitting curves of $\mathrm{SA}-\mathrm{Cu} / \mathrm{NG}$ and standard samples of $\mathrm{CuPc}$ and $\mathrm{CuO}$.

scope of the test (Figure S12), in agreement with the $\mathrm{RDE}$ results. The electron transfer number and $\mathrm{HO}_{2}^{-}$yields demonstrate that $\mathrm{SA}-\mathrm{Cu} / \mathrm{NG}$ possesses a $4 \mathrm{e}^{-}$reaction path for alkaline ORR.

Apart from the ORR performance, the long-term durability and methanol resistance ability of the catalysts are another pivotal concern for the actual applications for corresponding devices. As expected, the retention of current density of SA-Cu/NG electrodes reaches nearly $92 \%$ after the continuous $40000 \mathrm{~s}$ testing, apparently more stable than $20 \% \mathrm{Pt} / \mathrm{C}$ of $81.8 \%$ (Figure S13). Moreover, the chronoamperometric curves of $20 \% \mathrm{Pt} / \mathrm{C}$ drop rapidly when methanol is added at $400 \mathrm{~s}$, while the SA-Cu/NG has no effect, indicating that the SA$\mathrm{Cu} / \mathrm{NG}$ possesses robust immunity toward methanol crossover (Figure S14). 


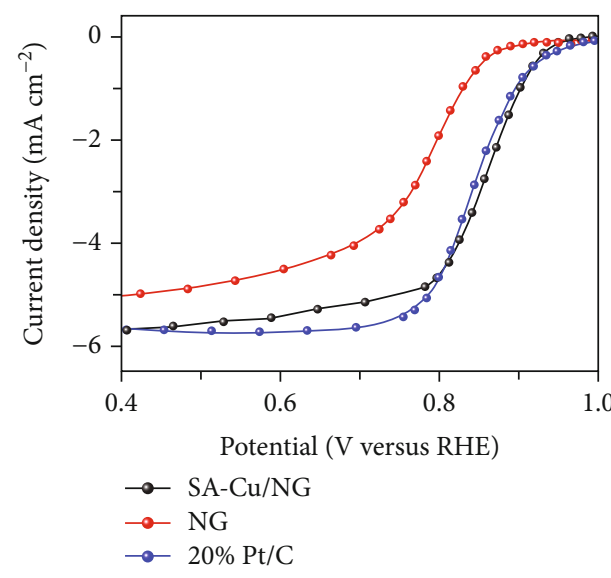

(a)

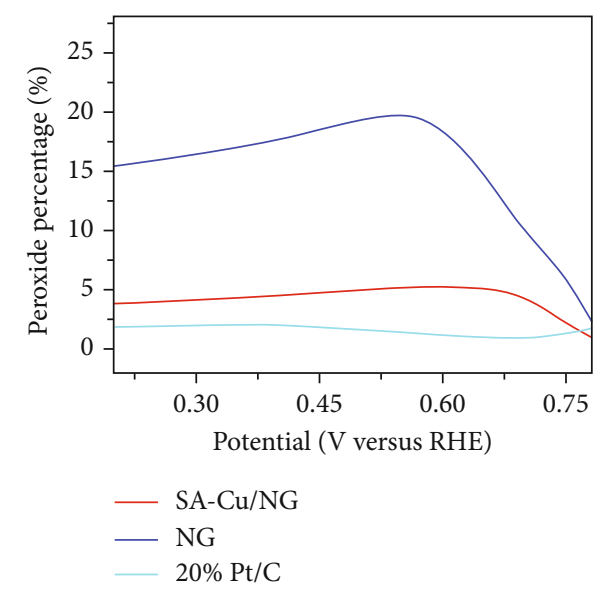

(c)

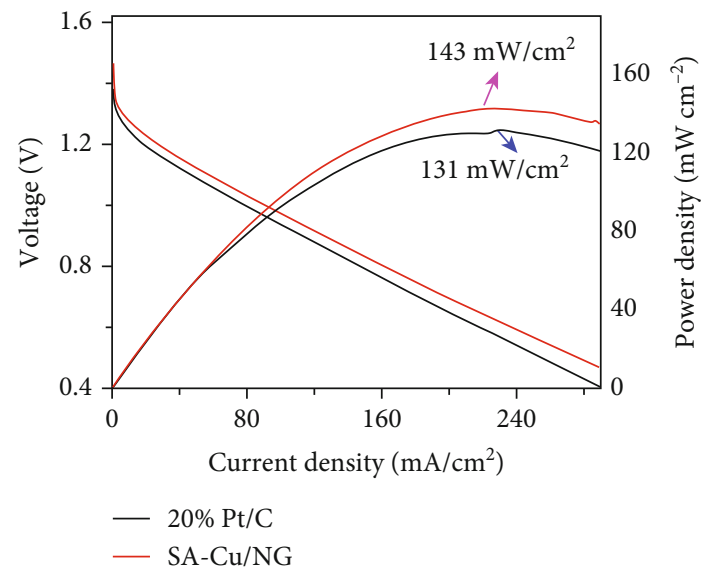

(e)

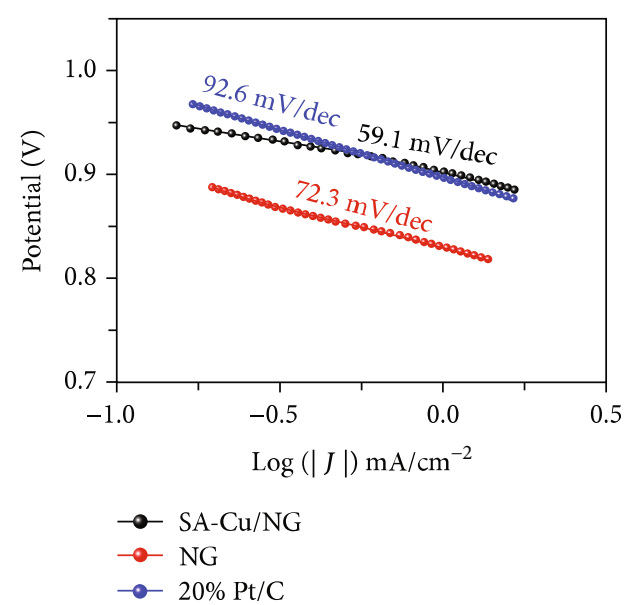

(b)

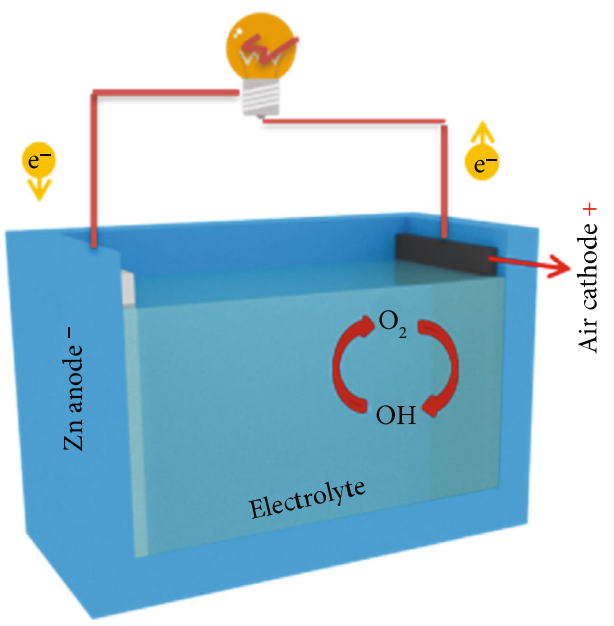

(d)

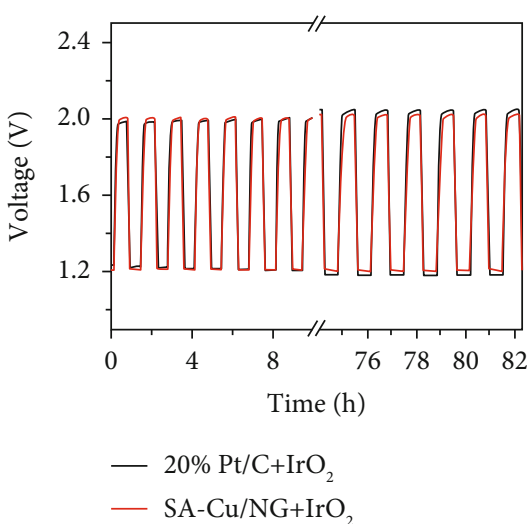

(f)

Figure 3: Electrocatalytic performance of samples and related devices. (a) LSV and (b) Tafel slope of fabricated samples and 20\% Pt/C in oxygen-saturated $0.1 \mathrm{M} \mathrm{KOH}$ electrolyte with $1600 \mathrm{rpm}$. (c) The $\mathrm{HO}_{2}^{-}$yields of fabricated samples and 20\% Pt/C derived from RRDE. (d) The schematic diagram of $\mathrm{Zn}$-air battery. (e) The discharging plots of SA-Cu/NG-based battery as well as $20 \% \mathrm{Pt} / \mathrm{C}$ constructed one. (f) The total $82 \mathrm{~h}$ voltage curves as well as the enlarged $1-10 \mathrm{~h}$ and $75-82 \mathrm{~h}$ cycle voltage for $\mathrm{SA}-\mathrm{Cu} / \mathrm{NG}+\mathrm{IrO}_{2}$ and contrast batteries.

2.3. Zn-Air Battery. We also assembled the primary Zn-air battery to deeply assess the catalytic activity of the SA$\mathrm{Cu} / \mathrm{NG}$ catalyst (Figure 3(d)). As illustrated in Figure S15, the open circuit voltage of the SA-Cu/NG-based battery attains $1.46 \mathrm{~V}$ and better discharge performance than the $20 \% \mathrm{Pt} / \mathrm{C}$ counterpart, with a $31 \mathrm{mV}$ and $35 \mathrm{mV}$ positive voltage at $50 \mathrm{~mA} / \mathrm{cm}^{2}$ and $100 \mathrm{~mA} / \mathrm{cm}^{2}$ compared to that of the $20 \% \mathrm{Pt} / \mathrm{C}$ counterpart (Figure 3(e)). Moreover, the peak 
power density reaches $143 \mathrm{~mW} / \mathrm{cm}^{2}$ at $221 \mathrm{~mA} / \mathrm{cm}^{2}$, which is $12 \mathrm{~mW} / \mathrm{cm}^{2}$ larger than the $20 \% \mathrm{Pt} / \mathrm{C}$ assembled battery (Figure 3(e)). To explore the cycle stability, a recyclable Znair battery is also assembled by using the combination of $\mathrm{SA}-\mathrm{Cu} / \mathrm{NG}$ and $\mathrm{IrO}_{2}$ as air cathode, and it exhibits robust cycling stability for continuous working for $90 \mathrm{~h}$ under $5 \mathrm{~mA} / \mathrm{cm}^{2}$ (Figure S16). Specifically, the round-trip overpotential of SA-Cu/NG+ $\mathrm{IrO}_{2}$-based battery increases to $0.82 \mathrm{~V}$ at about $80 \mathrm{~h}$ from the initial $0.78 \mathrm{~V}$. In contrast, a $15.5 \%$ increase of overpotential is observed for the $20 \% \mathrm{Pt} / \mathrm{C}$ $+\mathrm{IrO}_{2}$-based system (Figure 3(f)). Impressively, as shown in Figure S17, three SA-Cu/NG-based batteries in series can light up one LED display screen (the rated voltage $3.7 \mathrm{~V}$ ). Actually, the SA-Cu/NG catalyst exhibits outstanding ORR performance while also possesses robust durability in the Zn-air battery, which shows a promising perspective in the application of practical devices.

\subsection{Identification of Active Center of $S A-C u / N G$ by DFT} Calculation and Experiments. The above results indicate that $\mathrm{SA}-\mathrm{Cu} / \mathrm{NG}$ possesses outstanding ORR performance. Notably, it is not sensitive enough to obtain accurate coordination environment of $\mathrm{Cu}$ single atom by fitting $R$ space of samples with high similarity of the lengths of $\mathrm{Cu}-\mathrm{C}, \mathrm{Cu}-\mathrm{N}$, and $\mathrm{Cu}-\mathrm{O}$ bonds, as well as pyridine/pyrrole species. Therefore, we used DFT calculations to identify the atomically precise configuration of the active species of the SA-Cu/NG catalyst. In view of the EXAFS fitting on the nearest shell coordination of $\mathrm{Cu}$ atom, the coordination number $(\mathrm{CN})$ of $\mathrm{Cu}$ atom is around four, possibly including $\mathrm{Cu}-\mathrm{N} / \mathrm{Cu}-\mathrm{C} / \mathrm{Cu}-\mathrm{O}$ bonds. To precisely identify the active species, we constructed 32 types of all possible structures of $\mathrm{Cu}-\mathrm{N}_{x} \mathrm{C}_{y} \mathrm{O}_{z}$, as shown in Figure $\mathrm{S} 18$, in which one $\mathrm{Cu}$ atom of the SA-Cu/NG is connected to four nearest-neighbor atoms. All the structures are optimized using DFT relaxation. We first check the stability of the proposed possible configurations of SA-Cu/NG against metal aggregation at a theoretical level, in order to determine that the proposed possible catalysts are feasible experimentally (see Section S2 and Table S4 in Supplementary Materials for details). The $\mathrm{Cu}$ K-edge XANES curves indicate that the $\mathrm{Cu}$ valence of $\mathrm{SA}-\mathrm{Cu} / \mathrm{NG}$ is around +1.5 (Figure $2(\mathrm{c})$ ). The oxidation state of $\mathrm{Cu}$ single atom is obtained for all possible models via the normalization of Bader charge to corresponding standard samples $\left(\mathrm{Cu}, \mathrm{CuO}\right.$, and $\left.\mathrm{Cu}_{2} \mathrm{O}\right)$ with known oxidation states (see Figure S19) and shown in Table S4, which can confirm whether it is consistent with XANES analysis. Besides, the bond lengths between $\mathrm{Cu}$ and nearest neighbor are also summarized in Table S4, which can be compared with experimental EXAFS results (Table S2, $2.02 \AA$ ). The configurations with bond length deviation beyond $10 \%$ are regarded to be inconsistent with experimental characterization. All configurations meeting the screening criteria of stability, oxidation state, and bond length are labeled in red color in S4, which are selected for further investigations on ORR theoretical activity. It should be noted that Cu-pyridine- $\mathrm{N}_{4}$, which is often regarded as the active center of $\mathrm{Cu}$ single-atom catalysts on graphene in previous works [27-29, 31, 32], is also considered here in the case, although its oxidation state $(+1.94)$ is not in good agreement with XANES results.
To reveal the ORR electrocatalytic activity of $\mathrm{SA}-\mathrm{Cu} / \mathrm{NG}$, the computational hydrogen electrode method is used to examine the screened active sites by DFT calculations. Generally, the ORR process through an associative mechanism involves four-electron-four-proton transfer elementary steps on isolated metal sites, generating the adsorbed $\mathrm{OH}^{*}, \mathrm{O}^{*}$, and $\mathrm{OOH}^{*}$ intermediates. The optimized configurations of the intermediates and the corresponding adsorption free energies are shown in Figure S20 and Tables S5 S8. As shown in Figure S21 and Table S9, the free energy diagrams of all elementary steps in the ORR process on possible active sites of $\mathrm{SA}-\mathrm{Cu} / \mathrm{NG}$ are calculated at zero electrode potential $U$ versus RHE. Among all the tested active sites of SA-Cu/NG, the Cu2pd_N-2pd_C(side1) (marked as $\mathrm{Cu}-\mathrm{N}_{2} \mathrm{C}_{2}$ in the following content) possesses the highest ORR activity, and the onset potential ( $U_{\text {RHE }}^{\text {onset }}$ ) of all the tested active sites of SA-Cu/NG is apparently inferior to the onset potential $0.80 \mathrm{~V}$ of $\mathrm{Pt}(111)$. The inferior theoretical activity of all possible active sites of $\mathrm{SA}-\mathrm{Cu} / \mathrm{NG}$ to $\mathrm{Pt}(111)$ is entirely contradictory with the experimental results that $\mathrm{SA}-\mathrm{Cu} / \mathrm{NG}$ possesses superior ORR activity to $\mathrm{Pt} / \mathrm{C}$ (Figure 3(a)). These results demonstrate that the $\mathrm{Cu}-\mathrm{N}_{2} \mathrm{C}_{2}$ configuration should be the exact coordination environment of SA-Cu/NG rather than the real active species of alkaline ORR under working condition.

Previous research has demonstrated that, under the various electrocatalytic working conditions, the adsorbate might be adsorbed at the active center and the modified surface structures would significantly boost the activity of catalysts. For example, some fresh catalytic centers of SACs (e.g., $\mathrm{MN}_{4}-\mathrm{O}$ and $\mathrm{MN}_{4}-\mathrm{OH}$ ) were detected by in situ techniques, CHE model, and microkinetic analysis [14, 49, 50]. It can be inferred that the in situ generated oxygen adsorbate species may lead to reconstitutions of active sites of SA-Cu/NG and therefore enhance the ORR activity under working potential. Therefore, we systematically calculate preadsorption energies of $\mathrm{O}^{*}, \mathrm{OH}^{*}$, or $\mathrm{OOH}^{*}$ intermediates on the catalytic center of $\mathrm{SA}-\mathrm{Cu} / \mathrm{NG}$ under different electrode potentials and generate the surface Pourbaix diagrams (Figure S22), from which the thermodynamically stable surface phases can be determined. As depicted in Figure S22, those active sites of $\mathrm{SA}-\mathrm{Cu} / \mathrm{NG}$, where the $\mathrm{Cu}$ atoms are covered by a single $\mathrm{O}$ atom or a single $\mathrm{OH}$ at $\mathrm{ORR}$ working condition (at $0.7 \sim 1.23 \mathrm{~V}$ versus RHE) according to surface Pourbaix diagrams, are picked out for further studies on ORR theoretical activity. The adsorption free energies and reaction free energies of $\mathrm{Cu}-\mathrm{SACs}$ with surface reconstitution (Figures S22c, S22e, S22g, and 22h) are shown in Tables S10 S13, and the reaction intermediates and reaction free energy along ORR are displayed in Figures S23 and S24. Among these CuSACs with surface reconstitution under working potential, as for $\mathrm{Cu}-\mathrm{N}_{2} \mathrm{C}_{2}-\mathrm{O}$ (Figure $4(\mathrm{a})$ ), unless the output potential increases to $U_{\mathrm{RHE}}>0.84 \mathrm{~V}$, the free energy of the first proton-electron transfer step maintains downhill, and obviously, the first step of $\mathrm{O}_{2}$ to form $\mathrm{OOH}^{*}$ is the potentialdetermining step of ORR. Hence, the resultant $U_{\text {onset }}{ }_{\text {RHE }}$ of $\mathrm{Cu}-\mathrm{N}_{2} \mathrm{C}_{2}-\mathrm{O}$ is $0.84 \mathrm{~V}$ (Figure 4(b)) and higher than that for $\mathrm{Pt}(111)$ and $\mathrm{Cu}-\mathrm{N}_{2} \mathrm{C}_{2}$. Despite the reconstituted active sites on other candidates, their ORR activities are still sluggish 

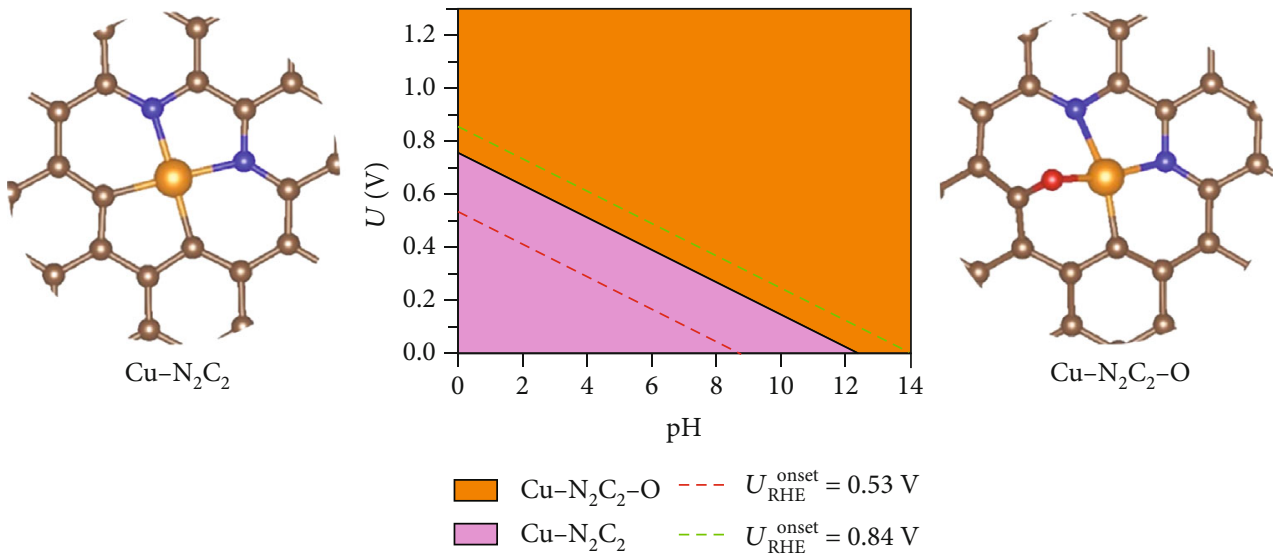

$\mathrm{Cu}-\mathrm{N}_{2} \mathrm{C}_{2}-\mathrm{O}$

(a)

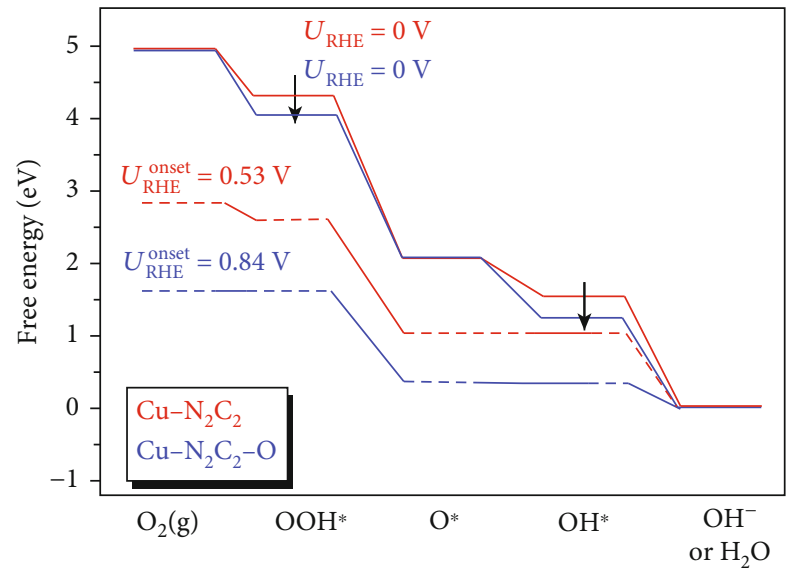

Reaction path

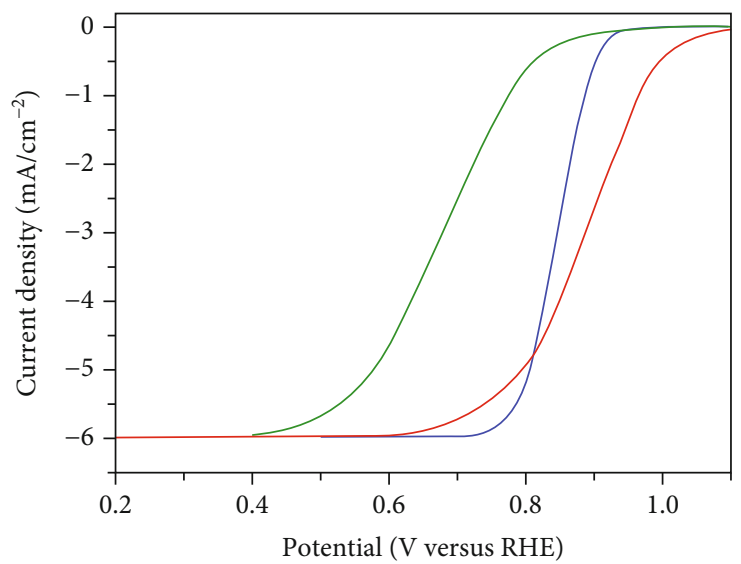

$$
\begin{array}{ll}
- & \mathrm{Cu}-\mathrm{N}_{2} \mathrm{C}_{2}-\mathrm{O} \\
& J_{\mathrm{k}}(\text { at } 0.85 \mathrm{~V})=12.6 \mathrm{~mA} / \mathrm{cm}^{2} \\
& E_{1 / 2}=0.89 \mathrm{~V} \\
& \mathrm{Pt}(111) \\
& J_{\mathrm{k}}(\text { at } 0.85 \mathrm{~V})=5.3 \mathrm{~mA} / \mathrm{cm}^{2} \\
& E_{1 / 2}=0.84 \mathrm{~V} \\
& \mathrm{Cu}-\mathrm{N}_{2} \mathrm{C}_{2}
\end{array}
$$

(c)

Figure 4: Density functional theory calculations of catalytic properties. (a) Surface Pourbaix diagrams and the configuration of Cu- $\mathrm{N}_{2} \mathrm{C}_{2}$ and $\mathrm{Cu}-\mathrm{N}_{2} \mathrm{C}_{2}-\mathrm{O}$. The values of onset potential are determined self-consistently. (b) Free energy for four-electron $\mathrm{ORR}$ on $\mathrm{Cu}-\mathrm{N}_{2} \mathrm{C}_{2}$ and $\mathrm{Cu}-\mathrm{N}_{2} \mathrm{C}_{2}-$ $\mathrm{O}$ at zero electrode potential and onset electrode potential with RHE. (c) Simulated polarization curve on $\mathrm{Pt}(111), \mathrm{Cu}-\mathrm{N}_{2} \mathrm{C}_{2}$, and $\mathrm{Cu}-\mathrm{N}_{2} \mathrm{C}_{2}-\mathrm{O}$ at $1600 \mathrm{rpm}$ rotation speed.

compared with $\mathrm{Pt}(111)$. There is another reaction mechanism for ORR, namely, dissociative pathway, where $\mathrm{O}_{2}$ is adsorbed and then dissociated into two $\mathrm{O}^{*}$ species on the $\mathrm{Cu}$ atom. However, the dissociation energy barrier of $\mathrm{O}_{2}$ on $\mathrm{SA}-\mathrm{Cu} / \mathrm{NG}$ is larger than $1 \mathrm{eV}$ (Figure S25), which is much higher than that of $\mathrm{O}_{2}$ on $\mathrm{Pt}(111)(0.48 \mathrm{eV})$ [51]. So, we believe that the associative mechanism is the most reasonable reduction pathway. To give an intuitive illustration, we further simulate their polarization curve and make a comparison with that of $\mathrm{Pt}(111)$ by means of microkinetic simulations (see Section 2.3 in Supplementary Materials for details). The predicted $E_{1 / 2}$ of oxygen-reconstituted $\mathrm{Cu}$ $\mathrm{N}_{2} \mathrm{C}_{2}$-O structure reaches $\sim 0.89 \mathrm{~V}$ versus RHE and outperforms $\mathrm{Pt}(111)$ by $\sim 50 \mathrm{mV}$ (Figure $4(\mathrm{c})$ ). Moreover, its $J_{\mathrm{k}}$ is larger than that of $\operatorname{Pt}(111)$. All theoretical outcomes show qualitatively reasonable consistency with experimental measurements, i.e., the oxygen-reconstituted structure $(\mathrm{Cu}-$ $\mathrm{N}_{2} \mathrm{C}_{2}-\mathrm{O}$ ) rather than the virgin $\mathrm{Cu}-\mathrm{N}_{2} \mathrm{C}_{2}$ configuration is the real active center of alkaline ORR under working potential.

2.5. ORR Catalytic Mechanism in the Oxygen-Reconstituted Active Species of SA-Cu/NG. To explore the reconstituted catalytic sites and complete ORR mechanism of SA-Cu/NG under working potential, the concerning adsorption structures of the intermediate and elementary steps are shown in Figure 5(a). Under working potential, the first step involves the single oxygen adsorbed on the $\mathrm{Cu}-\mathrm{C}$ bond on one side 

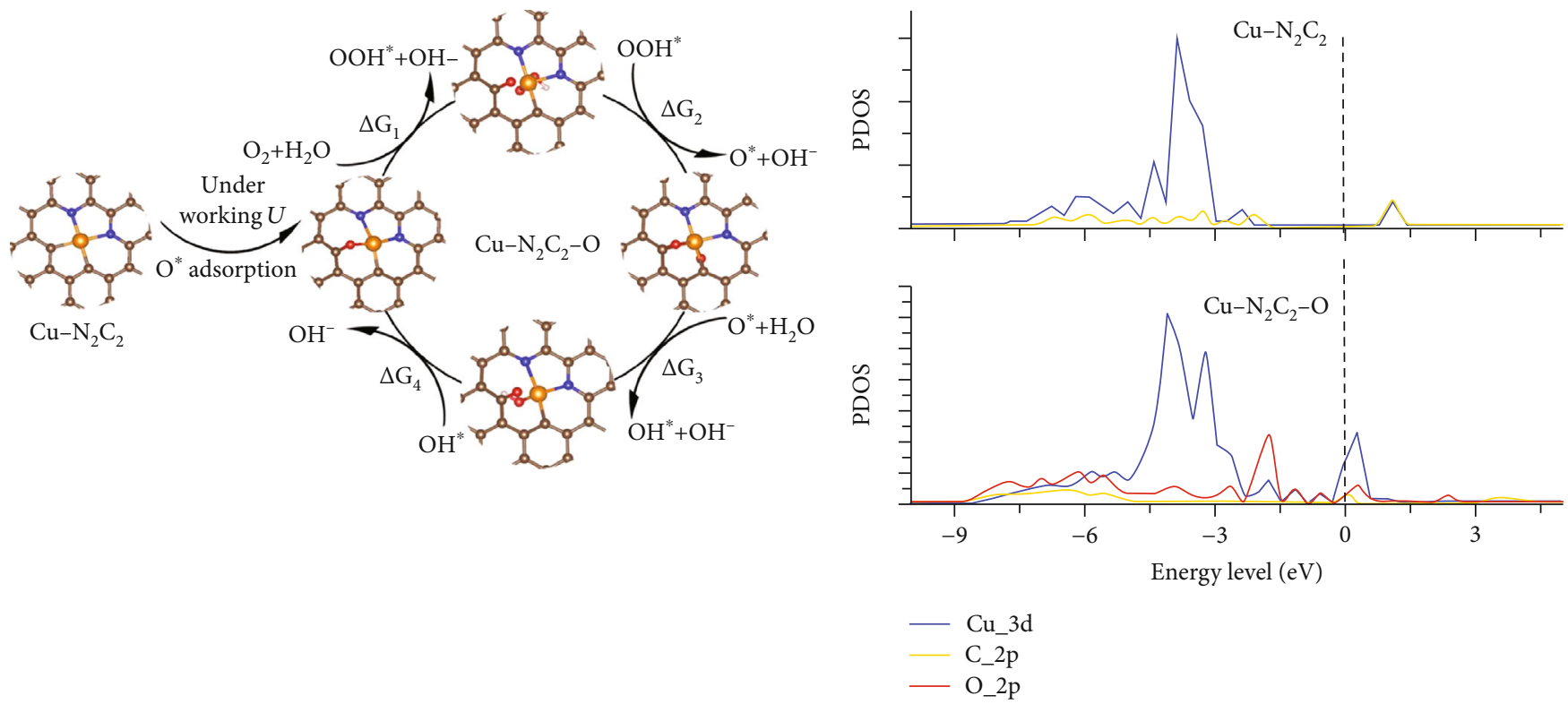

(a)
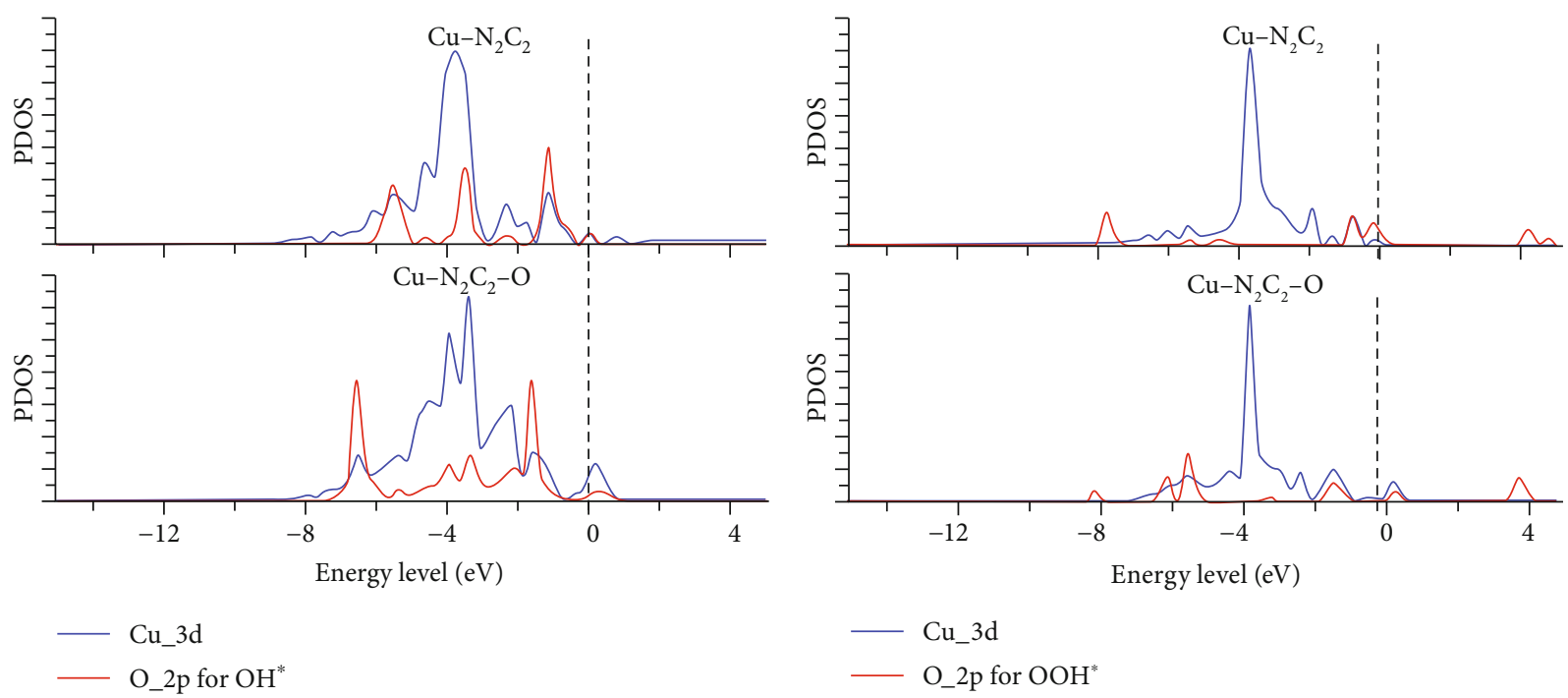

(c)

(d)

FIGURE 5: The catalytic mechanism. (a) Sketch map of the entire ORR mechanism of Cu-N-C single-atom electrocatalyst under ORR working potential. The brown, blue, red, white, and orange balls denote carbon, nitrogen, oxygen, hydrogen, and copper atoms. (b-d) Projected density of state analysis on (b) bare, (c) $\mathrm{OH}^{*}$ adsorbed, (d) $\mathrm{OOH}^{*}$ adsorbed Cu-2pd_N-2pd_C(side1), and Cu-2pd_N-2pd_C(side1)-O. "pd" means pyridine.

of graphene and the formation of the oxygen-reconstituted $\mathrm{Cu}-\mathrm{N}_{2} \mathrm{C}_{2}-\mathrm{O}$ active center. And $\mathrm{O}_{2}$ reacts with water on the other side of graphene through a series of proton-coupled electron transfer, finally resulting in the release of $\mathrm{OH}^{-}$. Actually, the adsorption or reaction process on both sides of SA$\mathrm{Cu} / \mathrm{NG}$ is rational, as confirmed in other SACs by previously reported in situ EXAFS $[49,52]$. The enhanced ORR activity from $\mathrm{Cu}-\mathrm{N}_{2} \mathrm{C}_{2}$ to $\mathrm{Cu}-\mathrm{N}_{2} \mathrm{C}_{2}-\mathrm{O}$ derives from the increased affinity of $\mathrm{Cu}$ atom for intermediates. Compared with $\mathrm{Cu}$ $\mathrm{N}_{2} \mathrm{C}_{2}, \mathrm{Cu}$ atom of $\mathrm{Cu}-\mathrm{N}_{2} \mathrm{C}_{2}-\mathrm{O}$ breaks up one $\mathrm{Cu}-\mathrm{C}$ bond to form a three-coordination configuration when binding either $\mathrm{OOH}^{*}$ or $\mathrm{OH}^{*}$. And the adsorption strength becomes stronger making the process of forming $\mathrm{OOH}^{*}$ and $\mathrm{OH}^{*}$ much more exothermic, which yields a higher onset potential. Figure 5(b) implies the important role of extraneous oxygen atom adsorption in weakening $\mathrm{Cu}-\mathrm{C}$ bond strength through bringing down the energy level of antibonding orbital. To understand the effect of reduced coordination number of $\mathrm{Cu}$ atom on higher stability of $\mathrm{OOH}^{*}$ and $\mathrm{OH}^{*}$ on $\mathrm{Cu}$ $\mathrm{N}_{2} \mathrm{C}_{2}$-O relative to $\mathrm{Cu}-\mathrm{N}_{2} \mathrm{C}_{2}$, it is valuable to probe the $\mathrm{d}$ orbital $\mathrm{Cu}$ site contributing to ORR. With the upward shifting of d-band of $\mathrm{Cu}$ atom from $\mathrm{Cu}-\mathrm{N}_{2} \mathrm{C}_{2}$ to $\mathrm{Cu}-\mathrm{N}_{2} \mathrm{C}_{2}-\mathrm{O}$ (see Figures 5(c) and 5(d)), the antibonding orbit upshifts, bringing about the reduced antibond orbit occupation and more robust adsorption for $\mathrm{OOH}^{*}$ and $\mathrm{OH}^{*}$. The same phenomenon, that the introduction of oxygen atom reduces the 
coordination number of $\mathrm{Cu}$ atom when binding $\mathrm{OOH}^{*}$ and $\mathrm{OH}^{*}$ and yields the higher adsorption strength, is also observed in other candidate active sites of SA-Cu/NG (Figure S23 and Tables S11 and S12). Thus, the above DFT provides strong analysis to verify the critical effect of the $\mathrm{CuN}_{2} \mathrm{C}_{2}$ configuration as well as oxygen reconstruction during operando operation for enhancing the ORR performance of SA$\mathrm{Cu} / \mathrm{NG}$.

2.6. Acidic ORR Tests. ORR performance at acidic condition for $\mathrm{SA}-\mathrm{Cu} / \mathrm{NG}$ is further evaluated. As seen in Figure S26, $E_{1 / 2}$ of $\mathrm{SA}-\mathrm{Cu} / \mathrm{NG}$ at acidic condition is only $0.48 \mathrm{~V}$ (versus $\mathrm{RHE}$ ) that is about $320 \mathrm{mV}$ inferior to $\mathrm{Pt} / \mathrm{C}$ in $0.5 \mathrm{M} \mathrm{H}_{2} \mathrm{SO}_{4}$ solution. The rather sluggishness performance of $\mathrm{SA}-\mathrm{Cu} / \mathrm{NG}$ for ORR under acidic condition is in line with the inferior theoretical half-wave potential of $\mathrm{Cu}-\mathrm{N}_{2} \mathrm{C}_{2}$ to $\mathrm{Pt}(111)$ in Figure 4(c), which implies that the virgin activity sites $(\mathrm{Cu}-$ $\mathrm{N}_{2} \mathrm{C}_{2}$ ) rather than the oxygen-reconstituted active species $\left(\mathrm{Cu}-\mathrm{N}_{2} \mathrm{C}_{2}-\mathrm{O}\right)$ of $\mathrm{SA}-\mathrm{Cu} / \mathrm{NG}$ are responsible for the inferior activity of SA-Cu/NG at acidic medium. In short, the finding of oxygen-reconstituted active species of SA-Cu/NG at alkaline media can successfully unveil the bottleneck puzzle of why the performance of ORR catalysts under alkaline condition is better than that under acidic condition.

\section{Conclusions}

In summary, we have synthesized a novel single-atom $\mathrm{Cu}$ catalyst $(\mathrm{SA}-\mathrm{Cu} / \mathrm{NG})$ with $\mathrm{Cu}-\mathrm{N}_{2} \mathrm{C}_{2}$ configuration, and $\mathrm{SA}-$ $\mathrm{Cu} / \mathrm{NG}$ shows the superior ORR ability to $\mathrm{Pt} / \mathrm{C}$ under alkaline medium while inferior activity to $20 \% \mathrm{Pt} / \mathrm{C}$ at acidic condition. Together with experimental data and DFT theoretical analysis, we for the first time found that the oxygenreconstituted $\mathrm{Cu}-\mathrm{N}_{2} \mathrm{C}_{2}-\mathrm{O}$ structure under working condition is the realistic ORR active species at alkaline conditions, while the virgin $\mathrm{Cu}-\mathrm{N}_{2} \mathrm{C}_{2}$ structure is the ORR active moiety at acidic media. The theoretical half-wave potentials of both oxygen-reconstituted $\mathrm{Cu}-\mathrm{N}_{2} \mathrm{C}_{2}-\mathrm{O}$ structure and virgin $\mathrm{Cu}-$ $\mathrm{N}_{2} \mathrm{C}_{2}$ structure are also in perfect agreement with experimental results at alkaline and acidic media, respectively. Adsorption of atomic oxygen intermediate $\mathrm{O}^{*}$ on the $\mathrm{Cu}-\mathrm{C}$ site yielded the reconstituted structure, and such $\mathrm{O}^{*}$ adsorption optimizes the electronic structure of $\mathrm{Cu}$ atom by breaking one $\mathrm{Cu}-\mathrm{C}$ bond during binding of $\mathrm{OH}^{*}$ and $\mathrm{OOH}^{*}$ reaction intermediates and therefore boosts ORR activity. The finding of reconstitution of surface active sites unveils the bottleneck puzzle of why the performance of ORR catalysts under alkaline electrolyte is better than that under acidic condition, which also offers a fresh perspective to advisably fabricate high-performance ORR electrocatalysts.

\section{Materials and Methods}

Experimental details including synthesis of samples, structure, and electrochemical characterizations of $\mathrm{SA}-\mathrm{Cu} / \mathrm{NG}$ and other samples and performance of SA-Cu/NG-based $\mathrm{Zn}$-air batteries are presented in Supplementary Materials. All computational details, including the DFT calculation process, screening of all possible structures of $\mathrm{Cu}$ single-atom catalysts, free energy diagram of Cu-SAC, and surfacereconstituted $\mathrm{Cu}-\mathrm{SACs}$ and surface Pourbaix diagrams of $\mathrm{Cu}-\mathrm{SACs}$, are also described in Supplementary Materials.

\section{Conflicts of Interest}

The authors declare that they have no conflict of interest.

\section{Authors' Contributions}

D.P.C. produced the initial thoughts. Y.L. and H.L. performed all the experiments. H.X. performed all the density functional theory calculations. L.Z. and R.C. contributed to the XAS measurement. X.Z., D.J.C., and Y.H. analyzed the data. L.Y., H.X., and D.P.C. composed the article. Y.L., H.X., and H.L. equally contributed to this work.

\section{Acknowledgments}

This work is supported by the National Key Research and Development Project from MOST (2019YFA0210300) and Outstanding Talent Fund from Beijing University of Chemical Technology.

\section{Supplementary Materials}

Section S1: experimental section. Section S2: density functional theory calculations. Section S3: supporting figures. Figure S1: XRD of SA-Cu/NG and NG. Figure S2: HAADF STEM of the SA-Cu/NG. (b) HRTEM of SA-Cu/NG. Figure S3: XPS of SA-Cu/NG and NG. Figure S4: N 1s XPS of SA$\mathrm{Cu} / \mathrm{NG}$. Figure S5: N 1s XPS of NG. Figure S6: Cu 2p XPS of SA-Cu/NG. Figure S7: $\mathrm{N}_{2}$ adsorption and desorption isotherms for $\mathrm{SA}-\mathrm{Cu} / \mathrm{NG}$ and $\mathrm{NG}$. Figure S8: the pore size of $\mathrm{SA}-\mathrm{Cu} / \mathrm{NG}$ and NG. Figure S9: $J_{\mathrm{k}}$ of $\mathrm{SA}-\mathrm{Cu} / \mathrm{NG}, \mathrm{NG}$, and $20 \% \mathrm{Pt} / \mathrm{C}$ in alkaline media. Figure S10: LSV of (a) SA$\mathrm{Cu} / \mathrm{NG}$ and (c) NG under $0.1 \mathrm{M} \mathrm{KOH}$ condition. K-L curves of (b) SA-Cu/NG and (d) NG. Figure S11: (a) LSV and (b) K$\mathrm{L}$ curves of $20 \% \mathrm{Pt} / \mathrm{C}$ under $0.1 \mathrm{M} \mathrm{KOH}$ solution. Figure S12: $n$ from $0.2 \mathrm{~V}$ to $0.8 \mathrm{~V}$ for SA-Cu/NG, NG, and $20 \% \mathrm{Pt} / \mathrm{C}$ in alkaline media. Figure S13: $i-t$ measurement of SA-Cu/NG and $20 \% \mathrm{Pt} / \mathrm{C}$ in alkaline media at $0.6 \mathrm{~V}$ (versus $\mathrm{RHE}$ ). Figure S14: $i-t$ measurement of SA-Cu/NG and $20 \% \mathrm{Pt} / \mathrm{C}$ by dropping $\mathrm{CH}_{3} \mathrm{OH}$ after $\sim 400 \mathrm{~s}$. Figure $\mathrm{S} 15$ : open circuit voltage of $\mathrm{SA}-\mathrm{Cu} / \mathrm{NG}$ assembled battery is measured by a universal meter. Figure S16: the stability test for SA-Cu/NG+IrO ${ }_{2}^{-}$ based battery for $90 \mathrm{~h}$. Figure S17: the picture of LED lighted by three $\mathrm{SA}-\mathrm{Cu} / \mathrm{NG}+\mathrm{IrO}_{2}$-based batteries. Figure S18: top view of all possible structures of Cu SACs. "pd" means pyridine, and "pr" means pyrrole. Figure S19: the scaling relationship between electron depletion of $\mathrm{Cu}$ atoms and valance state of $\mathrm{Cu}$. Figure S20: top view of relaxed configurations of intermediate along ORR adsorbed on Cu SACs. "pd" means pyridine, and "pr" means pyrrole. Figure S21: free energy diagram for $4 \mathrm{e}$ - transfer ORR on $\mathrm{Cu}$ single-atom catalysts at zero electrode potential and onset electrode potential with reversible hydrogen electrode (RHE) in an alkaline electrolyte. "pd" means pyridine, and "pr" means pyrrole. Figure S22: surface Pourbaix diagrams of Cu SACs. The values of 
onset potential are determined self-consistently. Figure S23: top view of relaxed configurations of intermediate along ORR adsorbed on intermediate-modified $\mathrm{Cu}$ single-atom catalysts. Figure S24: free energy diagram for $4 \mathrm{e}$ - transfer ORR on $\mathrm{Cu}$ single-atom catalysts at zero electrode potential and onset electrode potential with reversible hydrogen electrode (RHE) in an alkaline electrolyte. "pd" means pyridine, and "pr" means pyrrole. Figure S25: free energy diagram for $\mathrm{O}_{2}$ dissociation pathway on $\mathrm{Cu}-4$ pd_N, Cu-2pd_N-2pd_Cside1, and Cu-2pd_N-2pd_C-side1-O to form two adsorbed O*. "pd" means pyridine, and "pr" means pyrrole. Figure S26: (a) LSV curves of SA-Cu/NG and $20 \% \mathrm{Pt} / \mathrm{C}$ in $0.5 \mathrm{M}$ $\mathrm{H}_{2} \mathrm{SO}_{4}$ media. Section S4: supporting tables. Table S1: summary of XPS data of SA-Cu/NG and NG. Table S2: parameters of EXAFS fit for SA-Cu/NG. Table S3: the porosity of $\mathrm{SA}-\mathrm{Cu} / \mathrm{NG}$ and NG. Table S4: the valance of $\mathrm{Cu}$ atom, antiaggregation energy, antileach energy, and bond length of $\mathrm{Cu}$-neighbor atom for each possible active center of different $\mathrm{Cu}$ SACs shown in Figure S19. Table S5: values used for the corrections in determining the free energy of free $\mathrm{H}_{2}$ and $\mathrm{H}_{2} \mathrm{O}$ molecule. Table S6: DFT adsorption energies $\left(\Delta E_{\mathrm{ad}}\right.$, $\mathrm{eV})$, zero-point energy ( $\mathrm{ZPE}, \mathrm{eV})$, zero-point energy correction ( $\triangle \mathrm{ZPE}, \mathrm{eV})$, entropy $(T * S, \mathrm{eV}, T=298 \mathrm{~K})$, entropy correction $(T * \Delta S, \mathrm{eV}, T=298 \mathrm{~K})$, and adsorption free energies $\left(\Delta G_{\text {ad }}, e V\right)$ of the adsorbed $\mathrm{O}$ along the reaction pathway of ORR on different $\mathrm{Cu}$ SACs. Adsorption energies $(\mathrm{eV})$ were taken relative to energies of free $\mathrm{H}_{2}$ and $\mathrm{H}_{2} \mathrm{O}$ molecules. Table S7: DFT adsorption energies $\left(\Delta E_{\mathrm{ad}}, \mathrm{eV}\right)$, zero-point energy (ZPE, eV), zero-point energy correction $(\triangle \mathrm{ZPE}, \mathrm{eV})$, entropy $(T * S, \mathrm{eV}, T=298 \mathrm{~K})$, entropy correction $(T * \Delta S$, $\mathrm{eV}, \mathrm{T}=298 \mathrm{~K})$, and adsorption free energies $\left(\Delta \mathrm{G}_{\mathrm{ad}}, \mathrm{eV}\right)$ of the adsorbed $\mathrm{OH}$ along the reaction pathway of ORR on different $\mathrm{Cu}$ SACs. Adsorption energies $(\mathrm{eV})$ were taken relative to energies of free $\mathrm{H}_{2}$ and $\mathrm{H}_{2} \mathrm{O}$ molecules. Table S8: DFT adsorption energies $\left(\Delta E_{\mathrm{ad}}, \mathrm{eV}\right)$, zero-point energy (ZPE, $\mathrm{eV})$, zero-point energy correction $(\triangle \mathrm{ZPE}, \mathrm{eV})$, entropy $(T * S, \mathrm{eV}, T=298 \mathrm{~K})$, entropy correction $(T * \Delta S, \mathrm{eV}, T=$ $298 \mathrm{~K})$, and adsorption free energies $\left(\Delta G_{\mathrm{ad}}, \mathrm{eV}\right)$ of the adsorbed $\mathrm{OOH}$ along the reaction pathway of ORR on different $\mathrm{Cu}$ SACs. Adsorption energies $(\mathrm{eV})$ were taken relative to energies of free $\mathrm{H}_{2}$ and $\mathrm{H}_{2} \mathrm{O}$ molecules. Table S9: reaction free energy (in eV vs. RHE) of elementary step at $U_{\mathrm{RHE}}=0$ $\mathrm{V}$ and onset potential (in $\mathrm{V}$ vs. RHE) for ORR on different $\mathrm{Cu}$ SACs. Table S10: DFT adsorption energies $\left(\Delta E_{\mathrm{ad}}, \mathrm{eV}\right)$, zero-point energy (ZPE, eV), zero-point energy correction ( $\triangle \mathrm{ZPE}, \mathrm{eV})$, entropy $(T * S, \mathrm{eV}, T=298 \mathrm{~K})$, entropy correction $(T * \Delta S, \mathrm{eV}, T=298 \mathrm{~K})$, and adsorption free energies $\left(\Delta G_{\text {ad }}, e V\right)$ of the adsorbed $\mathrm{O}$ along the reaction pathway of ORR on O-reconstituted $\mathrm{Cu}$ SACs. Adsorption energies $(\mathrm{eV})$ were taken relative to energies of free $\mathrm{H}_{2}$ and $\mathrm{H}_{2} \mathrm{O}$ molecules. Table S11: DFT adsorption energies $\left(\Delta E_{\mathrm{ad}}, \mathrm{eV}\right)$, zeropoint energy (ZPE, eV), zero-point energy correction $(\triangle \mathrm{ZPE}$, $\mathrm{eV})$, entropy $(T * S, \mathrm{eV}, T=298 \mathrm{~K})$, entropy correction $(T * \Delta S, \mathrm{eV}, T=298 \mathrm{~K})$, and adsorption free energies $\left(\Delta G_{\mathrm{ad}}\right.$ , eV) of the adsorbed $\mathrm{OH}$ along the reaction pathway of ORR on O-reconstituted $\mathrm{Cu}$ SACs. Adsorption energies
(eV) were taken relative to energies of free $\mathrm{H}_{2}$ and $\mathrm{H}_{2} \mathrm{O}$ molecules. Table S12: DFT adsorption energies $\left(\Delta E_{\mathrm{ad}}, \mathrm{eV}\right)$, zeropoint energy (ZPE, eV), zero-point energy correction $(\triangle \mathrm{ZPE}$, $\mathrm{eV})$, entropy $(T * S$, eV, $T=298 \mathrm{~K})$, entropy correction $(T * \Delta S, \mathrm{eV}, T=298 \mathrm{~K})$, and adsorption free energies $\left(\Delta G_{\mathrm{ad}}\right.$ , eV) of the adsorbed $\mathrm{OOH}$ along the reaction pathway of ORR on O-reconstituted $\mathrm{Cu}$ SACs. Adsorption energies $(\mathrm{eV})$ were taken relative to energies of free $\mathrm{H}_{2}$ and $\mathrm{H}_{2} \mathrm{O}$ molecules. Table S13: reaction free energy (in $\mathrm{eV}$ vs. RHE) of elementary step at $U_{\mathrm{RHE}}=0 \mathrm{~V}$ and onset potential (in $\mathrm{V}$ vs. $\mathrm{RHE}$ ) for ORR on different O-reconstituted $\mathrm{Cu}$ SACs. (Supplementary Materials)

\section{References}

[1] D. Larcher and J. M. Tarascon, "Towards greener and more sustainable batteries for electrical energy storage," Nature Chemistry, vol. 7, no. 1, pp. 19-29, 2015.

[2] S. Chu and A. Majumdar, "Opportunities and challenges for a sustainable energy future," Nature, vol. 488, no. 7411, pp. 294303, 2012.

[3] B. Guan, L. Yu, and X. W. Lou, "A dual-metal-organicframework derived electrocatalyst for oxygen reduction," Energy \& Environmental Science, vol. 9, no. 10, pp. 3092-3096, 2016.

[4] K. Qu, Y. Zheng, S. Dai, and S. Z. Qiao, "Graphene oxidepolydopamine derived N, S-codoped carbon nanosheets as superior bifunctional electrocatalysts for oxygen reduction and evolution," Nano Energy, vol. 19, pp. 373-381, 2016.

[5] L. Yang, X. Zeng, W. Wang, and D. Cao, "Recent progress in MOF-derived, heteroatom-doped porous carbons as highly efficient electrocatalysts for oxygen reduction reaction in fuel cells," Advanced Functional Material, vol. 28, no. 7, article 1704537, 2018.

[6] L. Yang, X. Zeng, D. Wang, and D. Cao, "Biomass-derived FeNi alloy and nitrogen-codoped porous carbons as highly efficient oxygen reduction and evolution bifunctional electrocatalysts for rechargeable Zn-air battery," Energy Storage Material, vol. 12, pp. 277-283, 2018.

[7] L. Yang, Y. Lv, and D. Cao, "Co,N-codoped nanotube/graphene $1 \mathrm{D} / 2 \mathrm{D}$ heterostructure for efficient oxygen reduction and hydrogen evolution reactions," Journal of Materials Chemistry A, vol. 6, no. 9, pp. 3926-3932, 2018.

[8] H. Yu, A. C. Fisher, D. Cheng, and D. Cao, "Cu,N-codoped hierarchical porous carbons as electrocatalysts for oxygen reduction reaction," ACS Applied Materials \& Interfaces, vol. 8, no. 33, pp. 21431-21439, 2016.

[9] P. Song, M. Luo, X. Liu et al., "Zn single atom catalyst for highly efficient oxygen reduction reaction," Advanced Functional Materials, vol. 27, no. 28, article 1700802, 2017.

[10] L. Shang, H. Yu, X. Huang et al., "Carbon nanoframes: welldispersed ZIF-derived Co,N-co-doped carbon nanoframes through mesoporous-silica-protected calcination as efficient oxygen reduction electrocatalysts," Advanced Materials, vol. 28, no. 8, pp. 1712-1712, 2015.

[11] L. Jiao, R. Zhang, G. Wan et al., "Nanocasting $\mathrm{SiO}_{2}$ into metalorganic frameworks imparts dual protection to high-loading Fe single-atom electrocatalysts," Nature Communications, vol. 11, no. 1, article 2831, 2020.

[12] L. Jiao, "From metal-organic frameworks to single-atom $\mathrm{Fe}$ implanted $\mathrm{N}$-doped porous carbons: efficient oxygen 
reduction in both alkaline and acidic Media," Angewandte Chemie International Edition, vol. 57, pp. 8525-8529, 2018.

[13] Y. Chen, S. Ji, Y. Wang et al., "Isolated single iron atoms anchored on $\mathrm{N}$-doped porous carbon as an efficient electrocatalyst for the oxygen reduction reaction," Angewandte Chemie International Edition, vol. 56, no. 24, pp. 6937-6941, 2017.

[14] H. T. Chung, D. A. Cullen, D. Higgins et al., "Direct atomiclevel insight into the active sites of a high-performance PGM-free ORR catalyst," Science, vol. 357, no. 6350, pp. 479-484, 2017.

[15] H. Zhang, S. Hwang, M. Wang et al., "Single atomic iron catalysts for oxygen reduction in acidic media: particle size control and thermal activation," Journal of the American Chemical Society, vol. 139, no. 40, pp. 14143-14149, 2017.

[16] X. Wan, X. Liu, Y. Li et al., "Fe-N-C electrocatalyst with dense active sites and efficient mass transport for high-performance proton exchange membrane fuel cells," Nature Catalysis, vol. 2, no. 3, pp. 259-268, 2019.

[17] P. Chen, T. Zhou, L. Xing et al., “Atomically dispersed ironnitrogen species as electrocatalysts for bifunctional oxygen evolution and reduction reactions," Angewandte Chemie International Edition, vol. 56, no. 2, pp. 610-614, 2017.

[18] L. Yang, D. Cheng, H. Xu et al., "Unveiling the high-activity origin of single-atom iron catalysts for oxygen reduction reaction," Proceedings of the National Academy of Sciences, vol. 115, no. 26, pp. 6626-6631, 2018.

[19] P. Yin, T. Yao, Y. Wu et al., "Single cobalt atoms with precise $\mathrm{N}$-coordination as superior oxygen reduction reaction catalysts," Angewandte Chemie International Edition, vol. 55, no. 36, pp. 10800-10805, 2016.

[20] Y. He, S. Hwang, D. A. Cullen et al., "Highly active atomically dispersed $\mathrm{CoN}_{4}$ fuel cell cathode catalysts derived from surfactant-assisted MOFs: carbon-shell confinement strategy," Energy \& Environmental Science, vol. 12, no. 1, pp. 250-260, 2019.

[21] L. Yang, L. Shi, D. Wang, Y. Lv, and D. Cao, "Single-atom cobalt electrocatalysts for foldable solid-state Zn-air battery," Nano Energy, vol. 50, pp. 691-698, 2018.

[22] J. Li, M. Chen, D. A. Cullen et al., "Atomically dispersed manganese catalysts for oxygen reduction in proton-exchange membrane fuel cells," Nature Catalysis, vol. 1, no. 12, pp. 935-945, 2018.

[23] X. Xiong, Y. Li, Y. Jia et al., "Ultrathin atomic Mn-decorated formamide-converted $\mathrm{N}$-doped carbon for efficient oxygen reduction reaction," Nanoscale, vol. 11, no. 34, pp. 1590015906, 2019.

[24] M. Xiao, L. Gao, Y. Wang et al., "Engineering energy level of metal center: Ru single-atom site for efficient and durable oxygen reduction catalysis," Journal of the American Chemical Society, vol. 141, no. 50, pp. 19800-19806, 2019.

[25] C. Zhang, J. Sha, H. Fei et al., "Single-atomic ruthenium catalytic sites on nitrogen-doped graphene for oxygen reduction reaction in acidic medium," ACS Nano, vol. 11, no. 7, pp. 6930-6941, 2017.

[26] J. Wang, K. Wang, F. B. Wang, and X. H. Xia, "Bioinspired copper catalyst effective for both reduction and evolution of oxygen," Nature Communications, vol. 5, no. 1, article 5285, 2014.

[27] L. Cui, L. Cui, Z. Li et al., "A copper single-atom catalyst towards efficient and durable oxygen reduction for fuel cells," Journal of Materials Chemistry A, vol. 7, no. 28, pp. 1669016695, 2019.
[28] Z. Jiang, W. Sun, H. Shang et al., "Atomic interface effect of a single atom copper catalyst for enhanced oxygen reduction reactions," Energy \& Environmental Science, vol. 12, no. 12, pp. 3508-3514, 2019.

[29] Y. Qu, Z. Li, W. Chen et al., "Direct transformation of bulk copper into copper single sites via emitting and trapping of atoms," Nature Catalysis, vol. 1, no. 10, pp. 781-786, 2018.

[30] Z. Yang, B. Chen, and W. Chen, "Directly transforming copper (I) oxide bulk into isolated single-atom copper sites catalyst through gas-transport approach," Nature Communication, vol. 10, no. 1, article 3734, 2019.

[31] L. Feng, H. Gao-Feng, and N. Hyuk-Jun, "Boosting oxygen reduction catalysis with abundant copper single atom active sites," Energy \& Environmental Science, vol. 11, no. 8, pp. 2263-2269, 2018.

[32] H. Wu, H. Li, X. Zhao et al., "Highly doped and exposed $\mathrm{Cu}(\mathrm{i})-\mathrm{N}$ active sites within graphene towards efficient oxygen reduction for zinc-air batteries," Energy \& Environmental Science, vol. 9, no. 12, pp. 3736-3745, 2016.

[33] H. Xu, D. Cheng, D. Cao, and X. C. Zeng, "A universal principle for a rational design of single-atom electrocatalysts," Nature Catalysis, vol. 1, no. 5, pp. 339-348, 2018.

[34] K. Ding, A. Gulec, A. M. Johnson et al., "Identification of active sites in CO oxidation and water-gas shift over supported Pt catalysts," Science, vol. 350, no. 6257, pp. 189-192, 2015.

[35] J. T. S. Irvine, D. Neagu, M. C. Verbraeken, C. Chatzichristodoulou, C. Graves, and M. B. Mogensen, "Evolution of the electrochemical interface in high-temperature fuel cells and electrolysers," Nature Energy, vol. 1, article 15014, no. 1, 2016.

[36] G. Malta, S. A. Kondrat, S. J. Freakley et al., "Identification of single-site gold catalysis in acetylene hydrochlorination," Science, vol. 355, no. 6332, pp. 1399-1403, 2017.

[37] H. Wu, J. Geng, H. Ge, Z. Guo, Y. Wang, and G. Zheng, "Eggderived mesoporous carbon microspheres as bifunctional oxygen evolution and oxygen reduction electrocatalysts," Advanced Energy Materials, vol. 6, no. 20, article 1600794, 2016.

[38] Z. Zhang and P. Wang, "Highly stable copper oxide composite as an effective photocathode for water splitting via a facile electrochemical synthesis strategy," Journal of Materials Chemistry, vol. 22, no. 6, pp. 2456-2464, 2012.

[39] H. Shen, E. Gracia-Espino, J. Ma et al., "Atomically $\mathrm{FeN}_{2}$ moieties dispersed on mesoporous carbon: a new atomic catalyst for efficient oxygen reduction catalysis," Nano Energy, vol. 35, no. 5, pp. 9-16, 2017.

[40] Y. J. Sa, D. J. Seo, J. Woo et al., “A general approach to preferential formation of active $\mathrm{Fe}-\mathrm{Nx}$ sites in $\mathrm{Fe}-\mathrm{N} / \mathrm{C}$ electrocatalysts for efficient oxygen reduction reaction," Journal of the American Chemical Society, vol. 138, no. 45, pp. 1504615056, 2016.

[41] Z. Yao, "Molecule-level g- $\mathrm{C}_{3} \mathrm{~N}_{4}$ coordinated transition metals as a new class of electrocatalysts for oxygen electrode reactions," Journal of the American Chemical Society, vol. 139, no. 9, pp. 3336-3339, 2017.

[42] S. H. Ahn, X. Yu, and A. Manthiram, ““Wiring” Fe- $\mathrm{N}_{x}$-embedded porous carbon framework onto 1D nanotubes for efficient oxygen reduction reaction in alkaline and acidic media," Advanced Materials, vol. 29, no. 9, article 1606534, 2017.

[43] B. Ni, C. Ouyang, X. Xu, J. Zhuang, and X. Wang, "Modifying commercial carbon with trace amounts of ZIF to prepare 
derivatives with superior ORR activities," Advanced Materials, vol. 29, no. 27, article 1701354, 2017.

[44] Z. Liu, F. Sun, L. Gu et al., "Post iron decoration of mesoporous nitrogen-doped carbon spheres for efficient electrochemical oxygen reduction," Advanced Energy Materials, vol. 7, no. 22, article 1701154, 2017.

[45] B. Y. Guan, L. Yu, and X. W. Lou, "Formation of single-holed cobalt/N-doped carbon hollow particles with enhanced electrocatalytic activity toward oxygen reduction reaction in alkaline media," Advanced Science, vol. 4, no. 10, article 1700247, 2017.

[46] W. Jiang, L. Gu, L. Li et al., "Understanding the high activity of $\mathrm{Fe}-\mathrm{N}-\mathrm{C}$ electrocatalysts in oxygen reduction: $\mathrm{Fe} / \mathrm{Fe}_{3} \mathrm{C}$ nanoparticles boost the activity of Fe- $\mathrm{N}_{\mathrm{x}}$," Journal of the American Chemical Society, vol. 138, no. 10, pp. 3570-3578, 2016.

[47] H. Hu, L. Han, M. Yu, Z. Wang, and X. Lou, "Metal-organicframework-engaged formation of Co nanoparticle-embedded carbon@ $\mathrm{Co}_{9} \mathrm{~S}_{8}$ double-shelled nanocages for efficient oxygen reduction," Energy \& Environmental Science, vol. 9, no. 1, pp. 107-111, 2016.

[48] S. Yasuda, A. Furuya, Y. Uchibori, J. Kim, and K. Murakoshi, "Iron-nitrogen-doped vertically aligned carbon nanotube electrocatalyst for the oxygen reduction reaction," Advanced Functional Materials, vol. 26, no. 5, pp. 738-744, 2016.

[49] J. Li, S. Ghoshal, W. Liang et al., "Structural and mechanistic basis for the high activity of Fe-N-C catalysts toward oxygen reduction," Energy \& Environmental Science, vol. 9, no. 7, pp. 2418-2432, 2016.

[50] L. Cao, Q. Luo, W. Liu et al., "Identification of single-atom active sites in carbon-based cobalt catalysts during electrocatalytic hydrogen evolution," Nature Catalysis, vol. 2, no. 2, pp. 134-141, 2019.

[51] V. Tripković, E. Skúlason, S. Siahrostami, J. K. Nørskov, and J. Rossmeisl, "The oxygen reduction reaction mechanism on $\mathrm{Pt}(111)$ from density functional theory calculations," Electrochimica Acta, vol. 55, no. 27, pp. 7975-7981, 2010.

[52] Q. Jia, N. Ramaswamy, H. Hafiz et al., "Experimental observation of redox-induced $\mathrm{Fe}-\mathrm{N}$ switching behavior as a determinant role for oxygen reduction activity," ACS Nano, vol. 9, no. 12, pp. 12496-12505, 2015. 